\title{
NEW DIRECTIONS FOR RETRANSLATION RESEARCH: LESSONS LEARNED FROM THE ARCHAEOLOGY OF RETRANSLATIONS IN THE FINNISH LITERARY SYSTEM
}

\author{
Kaisa Koskinen 1 \\ ${ }^{1}$ University of Tampere, Tampere, Finland \\ Outi Paloposki \\ ${ }^{2}$ University of Turku, Turku, Finland
}

\begin{abstract}
In this article, we discuss the archaeological phase of our research into retranslating in the Finnish literary system. We address the issue from the point of view of the past and future development on retranslation research, focusing on methodology. We argue that for our understanding of the phenomenon to advance, the traditional case study orientation of retranslation research needs to be complemented with other, macro level approaches. We discuss what kinds of research questions our archaeological data allowed us to generate, how collecting bibliographical information of a larger set of translations allowed us to place individual case studies within the bigger picture, and how it allowed us to compare our findings to similar, macro level research done by other scholars. The next step for retranslation research will, we believe, consist of studies asking new questions on the basis of such macro level empirical evidence (tested on new, targeted data sets or case studies) and comparisons between these studies completed in different cultural, historical and literary contexts.

Keywords: Retranslation; Translation archaeology; Revision; Comparative approach
\end{abstract}




\title{
NOVOS RUMOS PARA A PESQUISA EM RETRADUÇÃO: LIÇÕES APRENDIDAS DA ARQUEOLOGIA DAS RETRADUÇÕES NO SISTEMA LITERÁRIO FINLANDÊS
}

\begin{abstract}
Resumo: Neste artigo, discutimos a fase arqueológica de nossa pesquisa acerca da retradução no sistema literário finlandês. Abordamos a questão do ponto de vista dos desenvolvimentos passados e futuros da pesquisa em retradução, com foco na metodologia. Defendemos que, para que nossa compreensão do fenômeno avance, a orientação tradicional para os estudos de caso na pesquisa em retradução deve ser complementada por outras abordagem, em macroníveis. Discutimos que tipo de perguntas de pesquisa nossos dados arqueológicos nos permitem gerar, de que modo a coleta de informações bibliográficas de um conjunto mais amplo de traduções nos permitiu encontrar um lugar para os estudos de caso individuais no quadro mais amplo, e de que modo nos permitiu comparar nossas descobertas com pesquisas em macronível de outros pesquisadores. $\mathrm{O}$ próximo passo para a pesquisa em retradução consistirá, segundo cremos, de estudos fazendo novas perguntas com base em tal evidência empírica de macronível (testada em conjuntos de dados novos, específicos, ou em estudos de caso), e em comparações entre estes estudos concluídas em diferentes contextos culturais, históricos e literários.

Palavras-chave: Retradução; Arqueologia da tradução; Revisão; Abordagem comparativa
\end{abstract}

\section{Introduction}

Retranslation research is a longstanding thread of scholarly activity within translation studies. To know where we are and where we might want to go next, it is useful to take stock of its internal history. Originally - from the 1980s onwards - and to an extent even today, retranslation research was dominated by French traductologie, with the publication of the special issue of Palimpsestes (1990) as a corner stone constantly referred to in retranslation literature even today. To briefly sum up the trajectory of research so far, during the 1990s much work focused on theoretical and philosophical contributions. The best known among these is Antoine Berman's 
essay in the aforementioned special issue. At the turn of the new millennium, Andrew Chesterman's reworking of Berman's ideas into the format currently known as the Retranslation Hypothesis paved way to a flow of case studies, many of them testing the hypothesis. This work has uncovered numerous interesting cases, but there is no comprehensive evidence for or against the hypothesis on a larger scale. It is by now safe to say that the Retranslation Hypothesis does not hold as a general explanatory model (see e.g. Paloposki and Koskinen 2004, Van Poucke, p. 94 and numerous other studies, among them Brownlie, Desmidt, Kuusi, Deane-Cox, which bring out the context-dependent nature of each translation).

Motivation - the 'why' question - is one of the most addressed issues in retranslation studies (Alvstad and Assis Rosa 14). In addition to the Retranslation Hypothesis, there is another line of enquiry springing from Berman's early theoretical writings and seeking to explain the need for retranslations: the alleged aging of translations. There is now a sustained body of work on aging (see Van Poucke for an overview). Both topics (RH and aging) draw largely on the case study approach and textual comparisons, producing information on the relations between different translations and their originals.

As studies accumulate, the limits of the (textual) case study approach are becoming evident. Different studies do not easily add up, as they employ different classifications and methods. For example, to test the RH one needs to find ways of measuring closeness to the original, and scholars have opted for many different techniques to do so (Koskinen and Paloposki 2015b, 76-83). The same applies to aging studies: Van Poucke notices the difficulty of operationalizing the concept of ageing (93). Hence, the results from different studies are not easily comparable. It is clear that we need to move beyond individual cases. This move can be achieved by meta-analysis (Van Poucke), by joint research agendas for many researchers working within one methodological framework (Berk Albachten), and by turning to new questions and new sets of materials.

In this article, we report some results from our work towards this third approach, that of turning to new directions. We, too, 
tested the RH when we first started looking at retranslations nearly twenty years ago, but we soon realized that it was a non sequitur and that we needed to rethink our approach and data. We then set ourselves two goals: to form a comprehensive picture of the whats, whens, whos, hows and whys of retranslating fiction into Finnish throughout the Finnish literary history, and to advance the understanding of the nature of retranslation in general and its relation to other related processes (revision and reprints, indirect translation). Among the questions that we wanted to answer were:

- How typical are the cases selected for analysis? How do we know?

- Is retranslating a constant phenomenon, or does it change culturally and/or temporally?

- How to combine results from different studies (cases, statistical and bibliographical searches, and contextualization)?

The more we looked into retranslation, the more burning the question of representability became: how do we know that the case studies we and other scholars were reporting were not the extreme or anomalous examples catching the eye of the researcher because of their special features or the fame of the original work or its author? Can we generalize from them to all retranslations? Can we generalize across time, or is the phenomenon of retranslation changeable? Can we identify eras of retranslation and eras of non-retranslations? - In the early 2000s, many scholars argued for a contemporary boom of retranslation (e.g. Collombat); can we identify such booms within the literary system of Finland? To answer these kinds of questions, we needed a multi-pronged approach. Bibliographical and statistical enquiries, the kind prompted by Anthony Pym's archaeology of translations and the Göttingen research team's 'external' translation history (Frank \& Kittel 39-41) enabled us to identify timelines and patterns of publication of retranslations. These findings then helped contextualize case studies and also produced more varying case material to build on. We are thus not relying on the most well-known 
cases only: the retranslations in our data come from different and varying contexts. A further dimension, then, is the contextualization of findings by studying epitexts (correspondence, publicity material, reviews) and general historical information.

In this article we focus on the role of the archaeological stage of our project. In section 2 we describe our research methodology, moving away from the close reading of different retranslations of individual source texts and collecting more systematic data with a diachronic perspective. In Section 3 we report some central findings of this archaeology. In section 4 we discuss the limits of this approach, and our subsequent return to case studies, now informed by the archaeological findings and also relying on contextual data and on comparisons with the results obtained by some other scholars (most notably Tiittula and Pokorn). In the concluding chapter we outline some future directions for retranslation research.

\section{Applied archaeology: Aiming at a more comprehensive picture}

In his methodology for translation history, Anthony Pym divides the writing of history into separate endeavors, one of which he labels translation archaeology, answering the questions of 'who translated what, how, where, when, for whom and with what effect' (Pym 5). This seemingly simple list engenders a large variety of research questions and methodological approaches: Pym himself admits that it "can include anything from the compiling of catalogues to the carrying out of biographical research on translators" (ibid). It may also involve textual analysis ('how') and a black box of sequels ('with what effect'). This archaeological approach can be delimited to allow for different sets of data or research questions to be perused. We focused on the whats, whens and whos (Pym 38-39) and combed bibliographies and statistics to produce lists of translations, retranslations and revised editions, not just of single source texts but of sets of source texts, translated 
at different times, from different languages. Tracing retranslation trajectories (histories of retranslation of single source works) and combining findings of retranslation patterns and frequencies, we wanted to target the question of representability, diachronically as well as synchronically. An added advantage was that this search produced us material for further case studies, thus allowing us to go beyond the bibliographical findings.

Translation archaeology is wrought with difficulties even at the best of times, because the translational nature of the texts is not always clear in traditional bibliographies. With retranslations, the problem is even more acute. For example, there is no single keyword or search facility to look for specifically retranslations in the national Finnish bibliography database Fennica; surely a wellknown problem for retranslation researchers everywhere. It is also probably the reason why much of retranslation research is focused on single cases and/or theoretical issues, resulting in a scarcity of overall empirical views or reviews of retranslating across genres, time periods or geographical locations (an important exception is the vast bibliographic research endeavor underway in Turkey; Berk Albachten). For a larger view - to know what has been retranslated and when - one has to comb through vast masses of bibliographical data, combining different search modes and perhaps enlisting the help of librarians and other researchers.

It follows that it is impossible to research everything that has been retranslated, even within one small(ish) language area such as Finnish. It is therefore all the more important to choose data sets that cross-cut the literary system of translations from a synchronic and diachronic perspective. Our archaeological data grew out of these concerns and came to consist of two different chronological data sets. The first one focused on a longitudinal history of translations and retranslations of a wide array of source texts, and the second one on retranslations published during one single year (2000). We will here focus on the first of these two (the second is reported in detail in Koskinen and Paloposki 2003): a book list called Tuhat vuotta - sata kirjaa ('One thousand years, one hundred books'). 
Originally a list of 100 books, compiled in Finland at the turn of the millennium and regarded as the 'all-time favourites' of Finnish readers, this list represents not only canonized literature but readers' tastes as well. For our purposes, it allowed us to use a preselected list of books considered culturally relevant but not handpicked by ourselves and therefore free of our own biases. Out of the 100 books, 52 were literary translations (the rest was Finnish literature and non-fiction) (Koskinen and Paloposki 2005). Our archaeological approach consisted of producing bibliographies to trace their translation trajectories to analyze what the Göttingen group calls "Comet's Tails" (Kometenschweife, Frank vi, 266), the translations into one language of one work. The bibliographical information allowed us to plot distributions: synchronic periods were studied with all the data in hand to identify 'rich' retranslation epochs, and timelines were studied diachronically to uncover patterns in retranslating frequencies.

Our archaeological data now consisted of full bibliographies of the 52 translated books from the 100 books list, resulting in 52 "comet's tails" - altogether 173 first translations, retranslations and revised versions. On the basis of these data we selected further case studies to look more closely into the textual profiles of different retranslations, finding innumerable mutations in the processing of texts from slight orthographic revising to major stylistic changes, from revision to new translating. In addition, we researched epitextual information on a number of cases ranging from translators' letters to the publisher's marketing material.

The data is still a sample, and we need to keep in mind that it does not give us a fully comprehensive view of the phenomenon we are trying to capture. But compared to stand-alone case studies it allows us to see at least indications of trajectories, trends and pathways that we can use to place case studies into a fuller picture of retranslation in general, and we can also begin to create new kinds of hypotheses, to be tested by collecting new targeted sets of data. 


\section{Retranslating and the Finnish literary field}

The Finnish language culture has always been a translational culture, and translations have been formative for the Finnish literary field as well: they are constitutive of our 'literary heritage'. Here, Finland shares parallels with many other smaller nations which have drawn on translations in establishing their literatures. What is perhaps atypical of Finland is the strong presence and prestige of the former major cultural influence, the Swedish language literature written in Finland. Several $19^{\text {th }}$ century works in Swedish are still considered as cornerstones of our literature, and literature in Swedish occupies an important position even today in the Finnish literary field. In the $19^{\text {th }}$ century, many of the source texts were thus domestic, not foreign. This applies to fiction and non-fiction alike. Both the national poet of Finland, J. L. Runeberg, and the 'father of Finland's children's literature', Zachris Topelius, wrote in Swedish. Their translated production includes some of the most canonized texts in Finnish, also figuring prominently in retranslation statistics from early on. Since literary translation only started during the 19th century (and in a more extensive manner only towards the end of the century), we did not assume there would be a lot of retranslations until well into the $20^{\text {th }}$ century. However, once we collected the archaeological data we could see unexpectedly many retranslations already in the late $19^{\text {th }}$ century and during the first years of the $20^{\text {th }}$ century , and the two 'grand old men' of Swedish-language literature in Finland were among the ones actively retranslated even during the first decades of their literary careers.

As to our other findings, some are quite solid, while others are more tentative, as the size of the data is still too small to contain a sufficient number of units within a particular set of parameters. For a long time in our research process the 52-book list was also a changeable set when it comes to the retranslations: we first collected the data in 2004, published our first findings in Koskinen and Paloposki 2005, but kept updating the bibliographies whenever a new retranslation and or a revised edition came up, until the end 
of 2013. In a small data set, subsequent shifts can make or break an argument. For example, in 2005 we tentatively argued that male authors may get retranslated more often than female authors (in their case, the publishers tend to go for revision rather than retranslation), and that the same might be the case for partially overlapping women's genres and children's literature as well (with many women authors) (Koskinen and Paloposki 2005, 194). We also found some evidence of women's reprocessing of earlier translations potentially being labelled more easily as revision, whereas similar activity by men was called retranslation. By 2013, a couple of new retranslations of children's and women's literature written by women and retranslated by women translators shifted the figures dramatically, making our case much more vague. The hypothesis is still plausible, as the findings may indicate changes in attitudes with time; literary fields have been known to operate in ways that marginalize genres perceived as feminine (see, e.g., Eagleton; Metzger). However, for more reliable results we would need to collect more targeted and comparable data sets.

Our data is too small for operating with subcategories such as the above, but some more general observations are quite robust. Among our most solid findings is the observation that getting retranslated is actually the normal case for any title with some lasting value in the literary system, and not a special event it has at times been portrayed to be. In Finland, retranslation has been considered the exceptional case and the alleged lack of retranslations has been lamented (Petäjä). The invisibility of previous (re)translations may have reinforced general ideas of retranslating. Retranslation, however, is much more prevalent than is thought, and books tend to get retranslated more times than is generally known. The comet's tails are both longer and more dense than we might assume. This is a sobering thought: the case study approach unavoidably highlights individual retranslations and makes them stand out; the archaeological perspective puts the cases into a context of constant and routinized reprocessing of texts. It also indicates that more scholarly attention might need to be directed at cases on non-retranslation, i.e. works that remain 
relevant and read but do not get retranslated or revised. A corpus of these special cases of "non-aging" translations might allow us to advance our understanding of the processes of aging.

The results also show that continuous retranslation is an ongoing process, and different versions can follow one another within short intervals (Table 1). This table only tells us how many of the retranslations appeared within a specific timespan; in order to interpret it fully we also need to know that, interestingly, towards the present day, our data is getting closer and closer to the 50 years' interval. That is, more books are now being retranslated after a fifty-year lapse in translation activity than what was the case previously. This 50-year span is often depicted as the "bestbefore-date" of translations. This finding indicates that the idea of aging may have become a self-fulfilling prophesy: a 50 years old translation is perhaps critically reviewed not because it is getting old but because it is a known "fact" in the system that translations age and need to be redone every 50 years - but not sooner. Contrary to what one might anticipate, this process is not making intervals between retranslations shorter but longer.

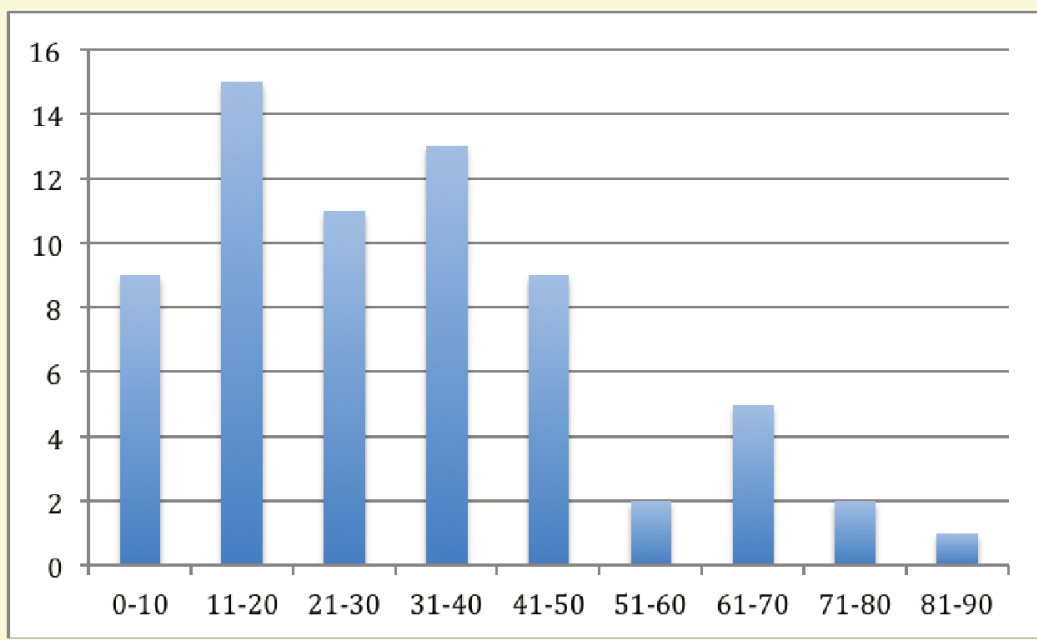

Table 1. The time span between different translations on the One thousand years, one hundred books list (years)

Cad. Trad., Florianópolis, v. 39, $\mathbf{n}^{0}$ 1, p. 23-44, jan-abr, 2019. 
Another assumption we had entertained was that retranslation and reprinting/revision are mutually exclusive strategies (Koskinen and Paloposki 2004). While this may be generally (although not always) true for the individual publisher, our archaeological data also shows interdependencies between the different modes of reprocessing. Indeed it is evident that retranslation boosts reprints, the most bare form of re-publishing translations: while retranslations get a lot of positive publicity (ibid., see also Koskinen and Paloposki 2015a), other publishers may cash on this publicity by bringing their older translation into the market, with a new cover to get their share of the renewed interest and the commercial value. Indeed, reprint and revision figures show that different versions often live side by side in the literary system, and the new one does not necessarily push the others aside. On the contrary, the first translation can sometimes outlive any subsequent retranslations. This kind of longevity might be taken as a sign of a "great translation", but contrary to Berman's argument (2), these are not necessarily always retranslations. It is also not only a question of translation quality. For example, retranslations may be short-lived if the publishing house folds down and there are no reprints.

As to the argument of retranslation booms, our data indicates that there may indeed be eras of retranslation in the Finnish literary culture. It shows a clear peak at the turn of the millennium, ostensibly supporting the claim of a boom in the 2000s. However, since the data was collected at that time, using a book list specifically aiming to highlight the continued relevance of a particular set of books for the Finnish readers, it stands to reason that the publishers wanted to benefit from that added visibility via selling new retranslations. The peak therefore has limited or no value as evidence (Table 2). Two other peaks are more reliable as indications of high retranslation activity, but again the data is too thinly spread across time to make strong claims. Still, it is highly interesting to find that peaks seem to appear in unexpected places. As mentioned above, the first era of high activity appears very early in our data, 
at the beginning of the 20 th century. In the $19^{\text {th }}$ century, retranslations were numerous and intervals between versions short, sometimes near-simultaneous. Why? There are a number of contextual explanations for the phenomenon. First, the rapid pace of language standardization made the language of the early translations seem obsolete. Second, publishing houses operated in isolation and in ignorance of what was being translated elsewhere. Third, Finland had not signed the Berne Convention, and copyright negotiations were not the order of the day. In sum, the young and small literary system invested a surprising amount of resources and energy into redoing translation work for works considered worthy of translation as opposed to commissioning translators of more titles.

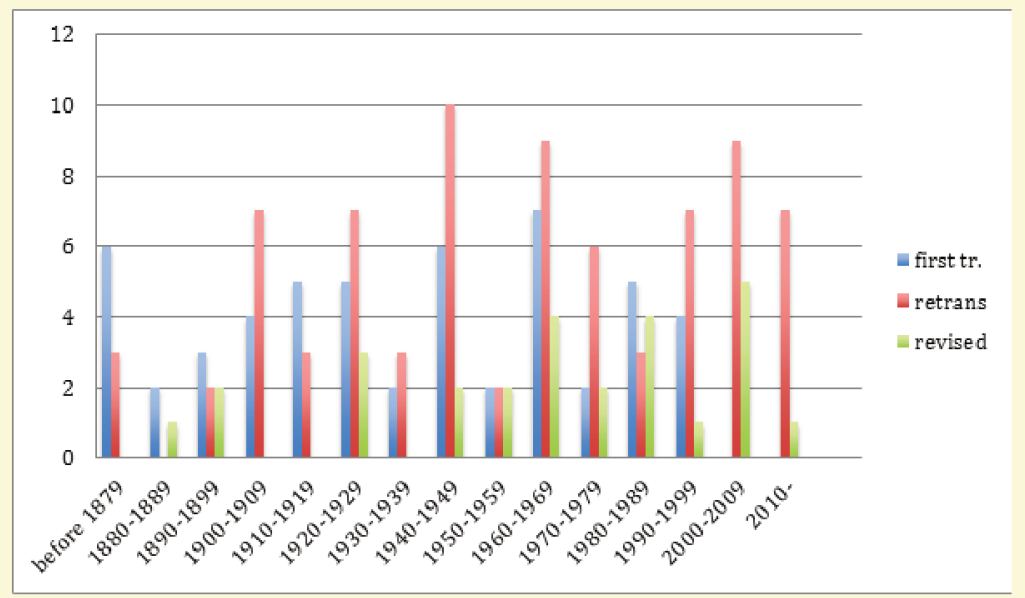

Table 2. First translations, retranslations and revised editions in One thousand years, one hundred books list (by decade)

The other era where we identify a tentative peak in our data is the late $1940 \mathrm{~s}$. This, too, might be somewhat unexpected. After the war, desire for reading was great, and many new publishing houses were founded. Retranslations of classic books were perhaps perceived as a good way of establishing a reputation in the market, 
and some of the peak may be explained by this. But there may be more to it than just the commercial interest, and the fluctuation of retranslation meets the high peak of modernism in Finland in a way that can be considered unexpected. During the early years of what was to become the greatest upheaval of the literary system in the 1950 s, i.e. the introduction of modernism, the system seems to have taken up speed for change not only from translations of new modernist works (to take up models from abroad) but also from new interpretations of some non-modernist classic. (For more information on modernism in the Finnish context, see Ameel)

It seems likely that similar to literary systems turning to translation at particular times and to fill a particular need (EvenZohar 46-47), systems may well exhibit similar fluctuation in their approach to retranslation. At particular points in time there may be booms of retranslations, and at other times eras of relative nonretranslation (in our data the 1980s appear to favor new translations over retranslations and revisions). All these claims, however, still remain hypotheses, to be tested with new data sets targeted specifically to this purpose, or of course by a more extensive coverage of all retranslations into Finnish, if it becomes possible to use more developed algorithms to extract all necessary information from the Fennica database in the future.

\section{Towards comparisons}

While archaeology can give us a global picture and some general trends, any full understanding of retranslation as a phenomenon also requires a significant amount of detailed text analysis of various cases. In our project, we proceeded from case studies to archaeology, but we also returned to case studies after it. With the added understanding gained from the overall view, and with a preselected set of 52 cases across time, in different genres and in a number of source languages, we were able to approach the issues of cases in a new, more strategic manner. The expanding body of 
retranslation research, often in the form of case studies conducted by other scholars, also gave us new ideas that we could test against our data set, running targeted comparisons.

"Case study" is a complex term, understood differently in different disciplinary and theoretical traditions (Koskinen and Paloposki 2015a, 17-18; see also Susam Sarajeva 2009). In retranslation research, the most typical case study approach consists of a particular (typically well known) classic text (typically a novel or a children's book) and its different (not always all) translations into a particular language. In a more holistic view, one could argue that our entire project is in fact a case study of retranslation in a particular literary system, i.e. the Finnish literature. The case studies that we have found most fruitful for our purposes are also more holistic than the ones focusing on an individual novel. In this chapter we briefly discuss how we used two previous case studies with a comprehensive scope: the exhaustive survey of literary retranslation from one language, German, into Finnish (Tiittula), and the role of retranslation of children's literature in the movement away from socialism in Slovenia (Pokorn). Comparisons can be seen as a fundament of Translation Studies (Tyulenev \& Zheng). In retranslation research, the default set-up has been the comparison of different translations of one source text. As mentioned above, the various case studies have not lent themselves to easy comparison because of differences in approaches. Here, we take another road: our comparisons below run on a macro level, as the cases involved are larger systems and not individual ST-TT pairs.

While it is (too) difficult and time-consuming to compile an exhaustive list of all retranslations from all languages into Finnish, many single language pairs offer more manageable data. The full history of German into Finnish retranslation, compiled by Liisa Tiittula, resulted in a number of findings that allowed for interesting comparisons with our larger data. Tiittula's dataset was heavily dominated by the pattern of two translations only for any single work (first translation and one retranslation). This is also an often held assumption by the general public in Finland, and a 
third or fourth retranslation is easily perceived as unexpected or even excessive. Looking at our data with a random selection of languages we could see that the global picture was much more varied. We hada number of sets of two translations only (some of them but by no means all overlapping with Tiittula's data), but also numerous cases of three, four or even more translations. Since we are talking about a young and small literary system, where there are not that many readers and the resources are scarce, it seems striking that there are so many cases of retranslation where the comet's tails may be both long and thick. We consider this finding worth analyzing further.

Another finding in the case of German literature translated into Finnish was a relative lack of recent retranslations (Tiittula), in contrast to the general claims of a retranslation boom elsewhere in the world. In our data - which covers more languages - no such lack is discernible. As discussed above, however, our data is likely to be biased in favor of retranslation in and after the turn of the new millennium, and it is therefore not the best test data for verifying whether a millennial boom of retranslations existed as retranslations completed around year 2000 may be overpresented. Together with the other finding of the second translation remaining the last translation in this particular language pair, however, the lack of recent retranslations from German still works as a reminder of the variabilities in cultural flows of influence. Language-specific tendencies may divert from the general trend, and the overall view of the phenomenon is not necessarily repeated across all subsets. It seems that interest in the 2000s has been directed towards other languages and literatures, away from a longstanding earlier relevance of German literature.

Tiittula's data partially overlaps with ours, and adds more insights into the case of the Finnish literary system. As discussed in the introduction, we set ourselves two aims: to map retranslation in Finnish literature and to also increase our understanding of the phenomenon of retranslating in general. It is in fact debatable how well and to what extent these two aims are compatible, and whether 
the second question can be answered on the basis of culture-specific observations only. Pokorn's monograph on retranslated children's literature in Slovenia was therefore a useful comparative test case for us, although its research questions and aims were different from ours, and although it was limited to children's literature whereas our data was more heterogeneous. Within the European context, Slovenia and Finland share a number of features which make comparisons relevant and interesting: they are both small and peripheral cultures, and their linguistic and cultural histories exhibit similar patterns, heavily influenced by the national revival of the $19^{\text {th }}$ century. In the $20^{\text {th }}$ century Europe, they also share a delicate position between the East and the West.

Pokorn's study revolves around political changes, in particular the effects of socialism in literature. Because of the potential similarities between Finland and Slovenia, some of Pokorn's findings aroused our curiosity, and the archaeological approach allowed us to explore whether similar tendencies could be found in our data. Identifying previous translator's becoming a persona non grata in the new political situation as one cause for retranslation (Pokorn 42-49) was particularly interesting, as Finland has also gone through political upheavals. The idea of political pressure behind translation decision-making (both in publishing and in the actual translating) comes up fairly often in connection with retranslation case studies, but we had not come across research indicating this kind of manipulation in the Finnish literary system, and we had not considered political causes as potential explanations for retranslations in our data. Pokorn's finding pushed us to look again at our data in more detail. The archaeological set-up allowed us to proceed systematically: we first analyzed all retranslations in our data from relevant time frames with focus on this particular viewpoint, second all retranslations of Russian literature, and third all titles classifiable as targeted for young readers, while paying particular attention to the profiles of the previous translators (Koskinen and Paloposki 2015b, 215-220). 
The results of these case studies were meagre. Although we could identify some politically active (both right and left wing) translators, we could not positively link retranslation processes to their political ideologies. This negative result did not allow us to identify political causes as a universally valid cause behind retranslation (which would have allowed us to move forward with our second research question) but it proved illuminating for our aim of understanding the special features of the Finnish literary system. In political history, Finlandisierung has come to mean a pragmatic approach adopted by small nations in their relation to neighboring super-powers, involving careful actions and selfcensorship. We tentatively assumed, therefore, that the Finnish literary system might have exhibited similar finlandisierte traits, avoiding translating potentially offensive titles and employing self-censorship at institutional level. Corrective measures would not then have been required. In terms of comparative retranslation research world-wide, cases such as this function as useful reminders of the contextualized nature of retranslation. We can draw two conclusions: seemingly/superficially similar political upheavals may be reflected differently in different cultures, and we need to exercise caution before assuming direct causalities. Another potential explanation to the different findings may also be found in genre differences in the two sets of data: while Pokorn focused on children's literature, we have a more heterogeneous data set. Although we did not find parallel developments in retranslations of titles for children and young readers in our data, we cannot automatically assume that with larger and more focused data we might not encounter cases similar to Pokorn's. Indeed, also our findings indicate that different genres may well be treated differently in retranslation (see section 3 above). To know more, we would need to collect comparative data of two genres from numerous historically, culturally and linguistically varied sources. 


\section{Conclusions and future directions}

Our archaeological data helped expand our research from single cases to trends and frequencies of the phenomenon (a more comprehensive diachronic and synchronic view) and direct our attention to phenomena hitherto unnoticed. Furthermore, archaeological enquiry brought out more material for further textual study, which we found was necessary in order to clarify the problematic classifications and scarce information in bibliographical data. Hence, the diachronic view allows us to see Finland as a much more varied scene of retranslating than what was assumed earlier. First, there are overall more retranslations across the gamut of different genres and at different time periods than what was the general assumption. Second, we have been able to come up with some tentative findings about specific retranslation peaks or periods of more active reprinting or revising practices. Also, the overlapping of the three processes - retranslation, reprinting and revising has come in high relief.

In spite of the small size of our sample, and the corresponding limits to generalizability, the archaeological exercise remains a valuable step in the process for a number of reasons. It allowed us to create a more holistic view of the phenomenon and to critically reassess some of the earlier assumptions and expectations held by ourselves or by others. The discovery that retranslation is a normal and widespread phenomenon and that non-retranslation may be more significant and rare than retranslation creates a new perspective for all existing and future case studies. The interplay of revision and retranslation, together with the related finding of the fuzziness of these two categories as literary practices, opens up a new area of research beyond prototypical cases of retranslation. Fundamentally, this fuzziness also creates the limits of the archaeological approach: the trajectories and trends discussed above were all based on our interpretation of database information, but our simultaneous case studies that were based on a close reading and comparison of different versions (Paloposki and Koskinen 2010) showed that

Cad. Trad., Florianópolis, v. 39, n $^{0}$ 1, p. 23-44, jan-abr, 2019. 
these are not always reliable and that texts are not always neatly classifiable as either retranslated or revised.

The archaeology of retranslations, thus, allows us to look beyond case studies and gain information on a longitudinal (diachronic) scale but also on a synchronic scale. This will add to the comprehensiveness of retranslation study as the cases remain no longer isolated but can be researched as parts of a larger phenomenon. We were also able to compare our results to those of other researchers from Finland and from other countries. Comparing our findings to results from other research going beyond single case studies allowed us to begin to trace the outlines of the phenomenon as a whole. This is a promising avenue for future research in retranslating. The challenge of the wide-spread, sprawling data is still there, but it can be tackled in smaller proportions with choices such as genre and source language. Finally, archaeological study also increases the number and coverage of case studies, which can now be researched on a wider scale and related to the bigger picture.

\section{References}

Alvstad, Cecilia and Alexandra Assis Rosa. "Voice in retranslation. An overview and some trends." Target, vol. 27, no. 1, 2015, pp. 3-24, doi 10.1075/ target.27.1.ooint. Accessed 7 Dec. 2017.

Ameel, Lieven. "Literary Modernism in Finland." The Routledge Encyclopedia of Modernism. Taylor and Francis, 2016. Date Accessed 16 Mar. 2018 https://www.rem.routledge.com/articles/literary-modernism-in-finland. doi:10.4324/9781135000356-REM1477-1

Berk Albachten, Özlem. "Retranslations in Ottoman and Modern Turkish Societies". Keynote, Retranslation in Context III conference, Ghent, Belgium, Feb $7^{\text {th }} 2017$. 
Berman, Antoine. "La Retraduction comme espace de traduction." Palimpsestes, vol. 13 , no. 4, 1990, pp. 1-7.

Brownlie, Siobhan. "Narrative Theory and Retranslation Theory." Across Languages and Cultures, vol. 7, no. 2, 2006, pp. 145-170.

Chesterman, Andrew. "A Causal Model for Translation Studies." Intercultural Faultines, edited by Maeve Olohan, St. Jerome, 2000, pp. 15-27.

Collombat, Isabelle. "Le XXIe siècle: l'âge de la retraduction." Translation Studies in the New Millennium, vol. 2, 2004, pp. 1-15.

Deane-Cox, Sharon. Retranslation: Translation, Literature and Reinterpretation. Bloomsbury, 2014.

Desmidt, Isabel. "(Re)translation Revisited." Meta, vol. 54, no 4, 2009, pp. 669-683.

Eagleton, Mary. "Genre and Gender" Re-Reading the Short Story." Ed. Claire Hanson. Basingstoke, Macmillan 1989, pp. 56-68.

Even-Zohar, Itamar. "Polysystem Studies." Special issue of Poetics Today, vol. 11, no. 1 .

Frank, Armin Paul. "Einleitung: Methodische Hinweise." Die literarische Übersetzung. Der lange Schatten kurzer Geschichten. Amerikanische Kurzprosa in deutschen Übersetzungen, edited by Armin Paul Frank, Erich Schmidt Verlag, 1989, pp. 195-199.

Frank, Armin Paul and Harald Kittel. "Der Transferansatz in der Übersetzungsforschung." Die literarische Übersetzung in Deutschland. Studien zu ihrer Kulturgeschichte in der Neuzeit, edited by Armin Paul Frank and Horst Turk, Erich Schmidt, 2004, pp. 3-67.

Koskinen, Kaisa and Outi Paloposki. Anxieties of influence: the voice of the first translator in retranslation. Target, vol. 27, no 1, 2015a, pp. 25-39. 
. Sata kirjaa, tuhat suomennosta. [One hundred books, one thousand translations] Helsinki: SKS. 2015b.

. "Retranslations in the Age of Digital Reproduction". Cadernos, vol. 1, 2003, pp. 19-38.

Kuusi, Päivi. Miksi näkökulma mиuttuи käännöksessä? Eksplisiittistämisen ja normaalistamisen selitysvoima ja seuraukset. [Why does point of view shift in translation? The explanatory power and effects of explicitation and normalization] Acta Universitatis Tamperensis 1638, Tampere University Press, 2011.

Metzger, Lore. "Modifications of Genre: A Feminist Critique of "Christabel" and "Die Braut von Korinth". Borderwork: Feminist Engagements with Comparative Literature. Edited by Margaret R. Higonnet, Shari Benstock and Celeste Schenck, Cornell: Cornell, UP 1994, pp. 81-99. http://www.jstor.org/stable/10.7591/j.ctt2 07g6sk? refreqid = excelsior\%3Ab6d81c564abd69e53824e4c01c7be895

Paloposki, Outi \& Koskinen, Kaisa. "Reprocessing texts. The fine line between retranslating and revising". Across Languages and Cultures, vol. 11, no 1, pp. $29-49$.

. "Thousand and One Translations. Retranslation Revisited". In: Gyde Hansen, Kirsten Malmkjaer and Daniel Gile (eds.) Claims, Changes and Challenges. Amsterdam/Philadelphia, John Benjamins, 2004, pp. 27-38.

Petäjä, Jukka. "Klassikko kääntyy harvoin kahdesti." [Only rarely does the classic get a second translation] Helsingin Sanomat 7.3.2004, C1.

Pokorn, Nike. Post-Socialist Translation Practices: Ideological Struggle in Children's Literature. John Benjamins, 2012.

Pym, Anthony. Method in Translation History. St. Jerome, 1998.

Susam-Sarajeva, Şebnem. "The Case Study Research Method in Translation Studies." The Interpreter and Translator Trainer 3/1 2009): 37-56. 
Tiittula, Liisa. "Finnische Neuübersetzungen deutschsprachiger Literatur." Trans-kom: Zeitschrift für Translationswissenschaft und Fachkommunikation, vol. 6, no. 1, 2013, pp. 140-170.

Tyulenev, Sergey and Binghan Zheng. "Toward comparative translation and interpreting studies." Translation and Interpreting Studies, vol. 12, no. 2, 2017, pp. 197-212, doi 10.1075/tis.12.2.01tyu.

Van Poucke, Piet. "Aging as a Motive for Literary Retranslation. A survey of case studies on retranslation." Translation and Interpreting Studies, vol. 12, no. 1, 2017, pp. 91-115, doi 10.1075/tis.12.1.05van.

Recebido em: 17/08/2018 Aceito em: 09/11/2018 Publicado em janeiro de 2019

Kaisa Koskinen. E-mail: kaisa.a.koskinen@uta.fi ORCID: https://orcid.org/0000-0003-2152-2388

Outi Paloposki. E-mail: outi.paloposki@utu.fi

ORCID: https://orcid.org/0000-0002-4920-3883 